\title{
ANALISIS FORMAL LUKISAN ANDI IAN SURYA
}

\author{
Muklisin $^{1^{*}}$, R.Triyanto ${ }^{2 *}$ \\ Program Studi Pendidikan Seni Rupa Jurusan Seni Rupa Fakultas Bahasa dan Seni \\ Universitas Negeri Medan \\ Jl. Willem Iskandar Pasar V Medan Estate, Kec, Percut Sei Tuan, Kab. Deli Serdang, Kode Pos 20371 \\ Sumatera Utara. Indonesia \\ Email:muklisinart95@gmail.com,triyantoraden75@gmail.com
}

\begin{abstract}
Abstrak
Penelitian ini bertujuan untuk mendeskripsikan hasil Analis is formal lukisan karya Andi Ian Surya. Analisis formal yakni melanjutkan inventarisasi deskriptif dengan mengumpulkan bukti-bukti untuk meng arahkan penafsiran karya deng an pertimbangan kebaikannya. Lukisan merupakan karya seni yang proses pembuatannya dilakukan dengan memulaskan cat dengan alat lukis.Populasi dalam penelitian ini adalah seluruh lukisan karya Andi Ian Surya yang diciptakan dari tahun 20013 sampai tahun 2018 sebany ak 500 karya. Sampel dalam penelitian sebany ak 6 kary a. Adapun metode yang digunakan dalam penelitian ini adalah metode deskriptif kualitatif Hasil penelitian menunjukkan karakteris tik Wama dalam karya lukis dari Andi Ian Surya yaitu menggunakan rentangan warna-warna murni agar kecerahan lukisan tetap terjaga, deng an pemanfaatan warna panas untuk bagian terang dan skema wama dingin untuk bagian gelap. Adapun menggunakan hitamdan putih hanya digunakan saat finishing untuk membuat bagian paling gelap dan terang.Goresan karya lukis karya dari Andi Ian Surya yaitu ekspresifimpresionis dengan goresan yang kasar dan tidak beraturan namun membentuk objek yang digambar. Tekstur dalam karya lukis Andi Ian Surya terdapat pada bagian tekstur nyata karena lukisan tersebut jika diraba maka akan sangat kasar permukaannya. Gelap terang pada lukis an karya Andi Ian Surya dihasilkan dari warna, tekstur dan kontras pada lukisan sehingga menimbulkan gelap-terang.Komposisi pada karya lukisan Andi Ian Surya menggunakan komposisi radial dan asimetris.
\end{abstract}

Kata Kunci: analisis, formal, lukisan.

\begin{abstract}
This study aims to describe the results of the formal analysis of paintings by Andi Ian Surya. Formal analysis, namely continuing descriptive inventory by gathering evidence to direct the interpretation of the work with consideration ofits goodness. Painting is a work of art whose manufacturing process is done by daubing paint with a painting tool. The population in this study are all paintings by Andi Ian Surya, created from 20013 until 2018, totaling 500 works. The sample in this study were 6 works. The method used in this study is a descriptive qualitative method. The results of the study show the characteristics of the colors in the paintings of Andi Ian Surya, namely using a range ofpure colors so that the brightness of the painting is maintained, by utilizing hot colors for the bright parts and cold color schemes for the dark parts. The use of black and white is only used when finishing to make the darkest and brightest parts. Scratches by Andi Ian Surya are expressive-impressionists with rough and irregular strokes but forming drawn objects. The texture in Andi Ian Surya's painting is in the real texture section because if the painting is touched it will be very rough on the surface. The dark light in Andi Ian Surya's paintings is produced from the colors, textures and contrasts in the paintings, giving rise to darkness. The composition in Andi Ian Surya's painting uses formal radial and asymmetric compositions.
\end{abstract}

Keywords: analysis, formal, painting.

\section{PENDAHULUAN}

Seni lukis adalah karya seni rupa dua dimensional yang menampilkan citra visual melalui unsur titik, garis, bidang, tekstur, dan warna.Sebagai karya seni murni, lukisan merupakan ungkapan bahasa artistik seseorang yang dituangkan dalam bidang dua dimensi. Banyak defenisi dari seni lukis menurut pandangan para pakar seni, tetapi memiliki tujuan yang sama berupa untuk ungkapan gagasan, ekspresi atau ide pada bidang dua dimensi.Analisis formal dalam penelitian ini dimaksudkan merupakan tahapan untuk mencoba menjelaskan objek yang ada dalam karya seni dengan dukungan beberapa data yang tampak secara visual. Proses ini dapat dimulai dengan cara menganalisis objek secara keseluruhan mengenai kualitas unsurunsur visual dan kemudian dianalisis bagian demi 
bagian, seperti menjelaskan tata cara pengorganisasian unsur-unsur elementer kesenirupaan seperti kualitas garis, bidang, warna, dan tekstur. Selain menjelaskan bagaimana komposis i karya secara keseluruhan dengan masalah keseimbangan, irama, pusat perhatian unsur kontras, dan kesatuan. Analis is formal dapat dimulai dari gagas an hingga kepada bagaimana tata cara proses perwujudan karya beserta urutannya. Analis is formal pada lukis an Andi Ian Surya dapat diartikan membedah lukisan secara keseluruhan mulai dari proses pembuatan karya, tema, ide, unsur- unsur dan elemen kesenirupaan hingga proses finishing dibahas secara tuntas. Dalam penelitian ini yang dimaksud analisis formal yaitu menjelaskan atau mendeskripsikan dan menilai secara keseluruhan unsur-unsur elemen kesenirupaan karya Andi Ian Surya. Dalam proses menciptakan karya lukis harus memiliki nilai estetik yang baik

Atinya seorang seniman harus memiliki kreativitas yang tinggi untuk menciptakan suatu karya yang sifatnya artistik. Sehubungan dengan itu, seorang seniman tidak terlepas dari faktor lingkungan, ide, penguasaan media, alat dan bahan serta teknik dalam melukis. Teknik melukis adalah cara yang dipakai seorang seniman dalam menggunakan bahan lukisannya, s ehingga menjadi suatu kebutuhan ketika ia bekerja. Lebih lagi pada dasarnya seorang pelukis/seniman.

Seniman berkarya setelah melalui proses interaksi dengan latar belakang ehidupannya. Dalam proses pewarnaan pada lukisan dalam pemilihan warna menjadi ciri khas tersendiripada Andi Ian Surya, yaitu selain Dnya) Andi tidak hanya meniru warna asli tetapi menggunakan rentangan warna murni. Setiap pelukis mempunyai kecenderungan tertentu dalam mewujudkan proses kreatifnya, untuk mendukung konsep dan ciri khas yang mengacu pada karyanya. Andi Ian Surya yang penuh dengan spontanitas dan totalitas dalamberkarya dan menciptakan ide, melukis dengan gaya dan pendekatan ekspresif merupakan cerminan dari watak pribadinya.

Kanvas berukuran satu meter persegi dapat dilukis dengan tuntas dalamrentan waktu satu s ampai dua jam Beragam warna, mulai dari tube warna primer, hingga warna yang di olahnya dari campuran berbagai wama di goreskan kan dengan tektik eks presif di atas kanvas. Pisau palet dan kuas dengan bulu yang kasar memberi bantuan untuk membentuk kesan ekspresif dalam lukisanya. Jika memandang secara visual pada karyakarya lukisannya objek yang digambarkan dalam lukisan Andi Ian Surya bermacam-macam antara lain
Gorga : Jurnal Seni Rupa

Volume 09 Nomor 02 Juli-Desember 2020

p-ISSN: 2301-5942 | e-ISSN: 2580-2380

alam, manusia, benda dan lain sebagainya sesuai apa yang Andilihat dan ingin ia lukiskan ke kanvas namun yang paling dominan adalah potret. Karya lukis Andi Ian Surya sudah banyak dikoleksi oleh kolektor seni dan menikmat seni mulai dari pengusaha, para pejabat dan galeri-galeri seni.

\section{KAJIAN TEORI}

\section{Analisis}

Ensiklopedia Indonesia, (1988 : 19) mendefinisikan analisis adalah cara memeriksa suatu masalah untuk menemukan semua unsur dasar dan hubungan antara unsur-unsur yang bersangkutan, oleh karena itu masalah yang diperiksa dapat diketahui susunannya. Dalam penelitian ini, yang dimaksud menganalisis lukis an Andi Ian Surya.Analisis (dari English Analysis) berasal dari kata analusis yang artinya pelepasan. Analisis adalah pengujian atas sesuatu yang secara keseluruhan kompleks dengan cara memecahmecahnya jadi bagian perbagian dan mengobservasinya satu persatu.

Analisis dalam seni rupa merupakan hubungan seperti ukuran, bentuk, warna, tekstur, ruang dan volume mendorong pemeriksaan lengkap dari karya seni. Mengungkapkan proses pengambilan keputusan dari seniman yang menginginkan untuk karya seni (Wiratno, 2020 : 218). Analis is adalah penyelidikan yang menguraikan data dan mengelompokkan data ters ebut, (Halawa, 2020 : 194).

Berdas arkan pendapat di atas maka dapat disimpulkan Analisis ialah pengujian, menguraikan atas sesuatu yang secara keseluruhan dengan cara memecah dan mengovservasi satu persatu agar dapat memahaminya secara keseluruan dari sesuatu yang dianalis is .

\section{Analisis Formal}

Analisis formal dapat dimulai dari gagasan hingga kepada bagaimana tata cara proses perwujudan karya bes erta urutannya (Feldman dalam Bahari, 2014 : 10 ). Analisis formal yakni melanjutkan inventarisasi deskriptif dengan mengumpulkan bukti-bukti untuk mengarahkan penafsiran karya dengan pertimbangan kebaikannya, (Kartika, 2007: 64 ).

Berdas arkan pendapat di atas maka dapat disimpulkan bahwa analisis formal merupakan tahapan yang bertujuan untuk mencoba menjelaskan objek atau karya yang dikritik dengan cara menganalis is dan menilai secara keseluruhan kualitas unsur-unsur elemen kesenirupaan atau data yang tampak secara visual dengan berbagai pertimbangan.analis is formal dapat diarti kan membedah lukis an secara keseluruhan mulai 
dari proses pembuatan karya,tema,ide,unsur unsur dan elemen kes enirupaan hingga proses finishing di bahas secara tuntas.

\section{Seni Lukis}

Lukis merupakan cabang dari seni rupa yang cara pengungkapannya diwujudkan melalui karya dua dimensional dimana uns ur-unsur pokok dalam karya dua dimensional ialah garis dan warna menurut Soedarso ( 1990). Seni Lukis dapat dikatakan sebagai suatu ungkapan pengalaman estetik seseorang yang dituangkan dalambidang dua dimensi (dua matra ), dengan menggunakan mediumrupa, yaitu garis, wama, tekstur, shape, dan sebagainya Dharsono ( 2004 : 36 ) Lebih lanjut lagi didalam Endiklopedia Indonesia disebutkan "Seni lukis adalah pernyataan tentang kenyataan dengan memakai macam grafis dan warna. Susanto ( 2012 :70 ) menjelaskan seni lukis pada das arnya merupakan bahasa visual dari pengalaman artistik maupun ideologis yang menggunakan wama dan garis, guna mengungkapkan perasaan, mengekspresikan emosi, gerak, ilusi maupun ilus trasi dari kondisi subjektif ses eorang.

Berdasarkan beberapa definisi diatas dapat disimpulkan bahwa seni lukis pada lukis an merupakan ungkapan atau pengekspresian ide, emosi dan pengalaman artistik yang diekspresikan dalam bidang kanvas menggunakan garis, warna, teks tur, ruang dan bentuk melalui pros es cipta, ras a, karsa yang bertujuan untuk menciptakan karya yang diinginkan oleh penciptanya.

\section{METODE PENELITIAN}

Metode penelitian merupakan struktur yang sangat penting, karena berhasil tidaknya demikian juga rendahnya kualitas hasil penelitian sangat ditentukan oleh ketetapan dalam memilih metode penelitian. Adapun metode yang digunakan dalam penelitian ini adalah metode deskriptif kualitatif dengan langkahlangkah sebagai berikut: observasi berperan serta (participant observation), wawancara mendalam (indepth interview) dan dokumentasi untuk men getahui permasalahan yang akan dibahas objek peneliti yaitu pengamatan langsung ke lapangan. Maka dalamhalini penulis akan mendeskripsikan data-data yang diperoleh berdasarkan subjek yang diteliti dengan instrumen penelitian yang telah ditentukan.

\section{HASIL DAN PEMBAHASAN}

\section{Hasil}

Data penelitian karya Andi Ian Surya diperoleh dari metode observasi (peninjauan studio dan galeri), dokumentasi (membuktikan kebenaran lukisan dan
Gorga : Jurnal Seni Rupa

Volume 09 Nomor 02 Juli-Desember 2020 p-ISSN: 2301-5942 | e-ISSN: 2580-2380

mempotonya) dan wawancara atau interview (percakapan dengan maksud meminta keterangan), semua metode ini memfokus kan pada pelukis Andi Ian Surya secara langsung. Penganalis isan hasil penelitian teknik nya diperoleh dari dokumentasi karya Andi Ian Surya melalui media kamera diambil foto lukis an nya sebany ak 6 karya yang telah dipilih deng an objek yang berbeda dan dianggap cukup mewakili keselunan lukisan realisnya. Penelitian ini dipilih berdasarkan analisis formal Karya lukis Andi Ian Surya.

\section{1). Karya 1}

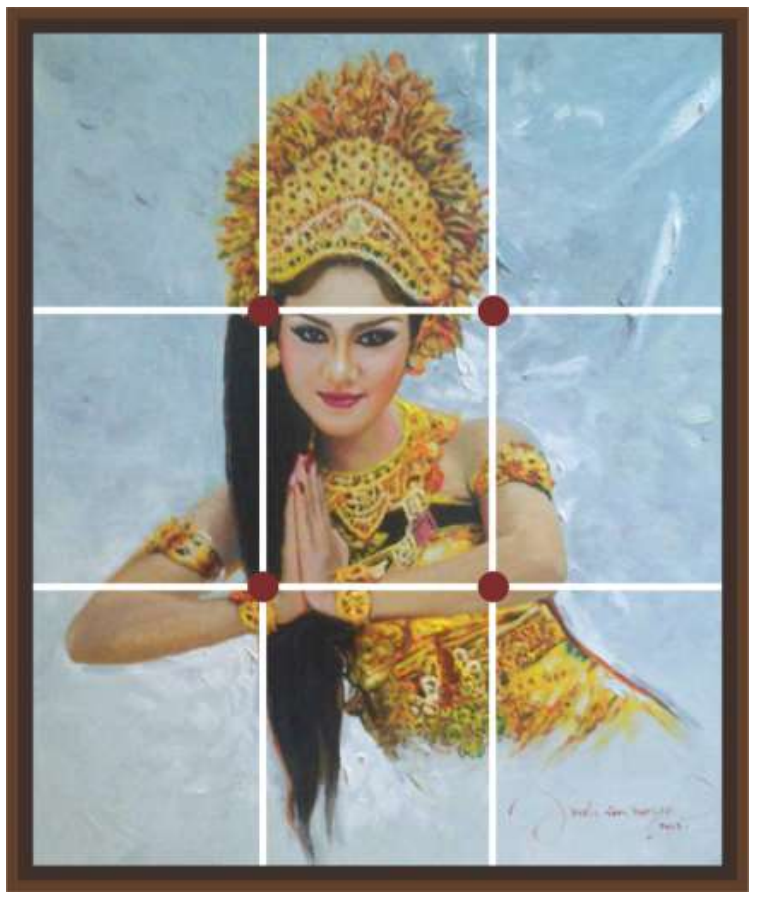

Gambar 1. Penari Bali (Sumber: Andi Ian Surya, 2013) 


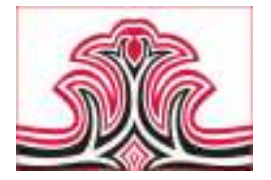

2). Karya 2

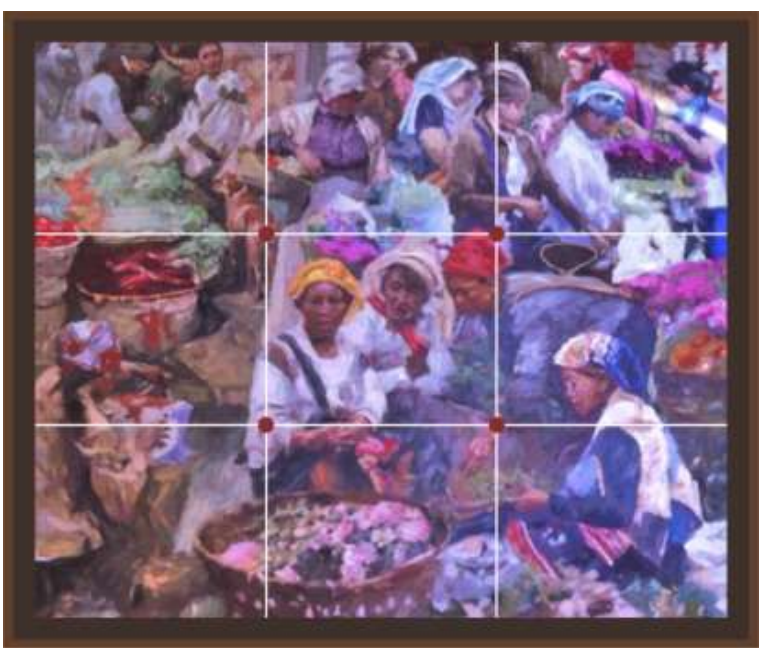

Gambar 2. Pasar Berastagi

(Sumber: Muklisin, 2018).

\section{3). Karya 3}

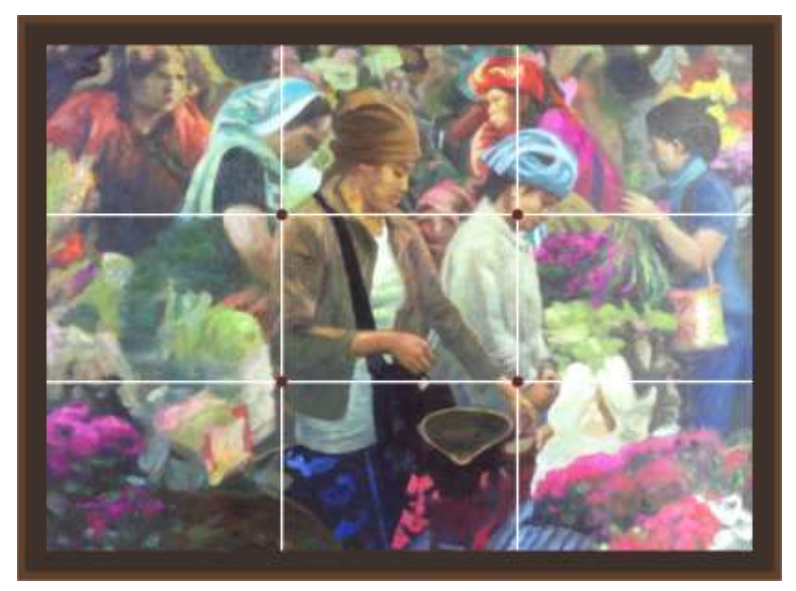

Gambar 3. Pasar Bunga

(Sumber: Muklisin, 2018)
Gorga : Jurnal Seni Rupa

Volume 09 Nomor 02 Juli-Desember 2020

p-ISSN: 2301-5942 | e-ISSN: 2580-2380

\section{4). Karya 4}

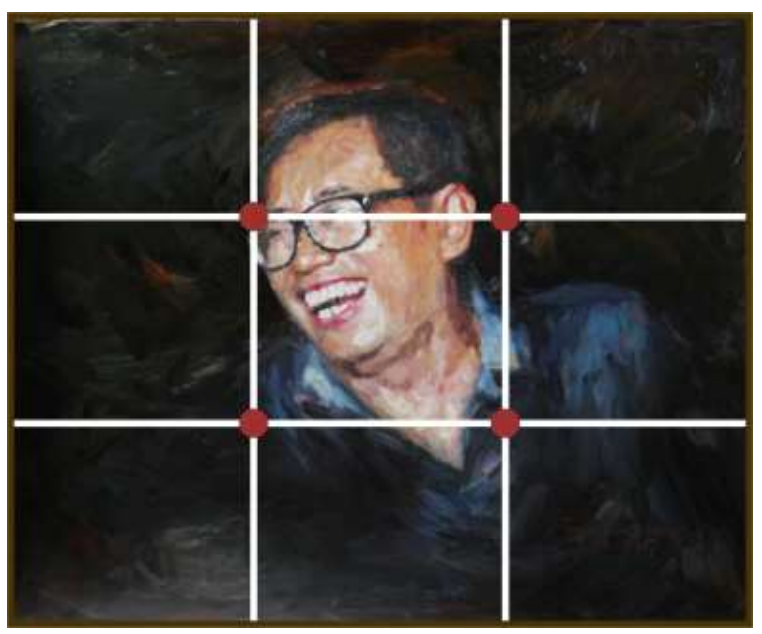

Gambar 4. Anang Sunoto

(Sumber: Andi Ian Surya, 2018).

5). Karya 5

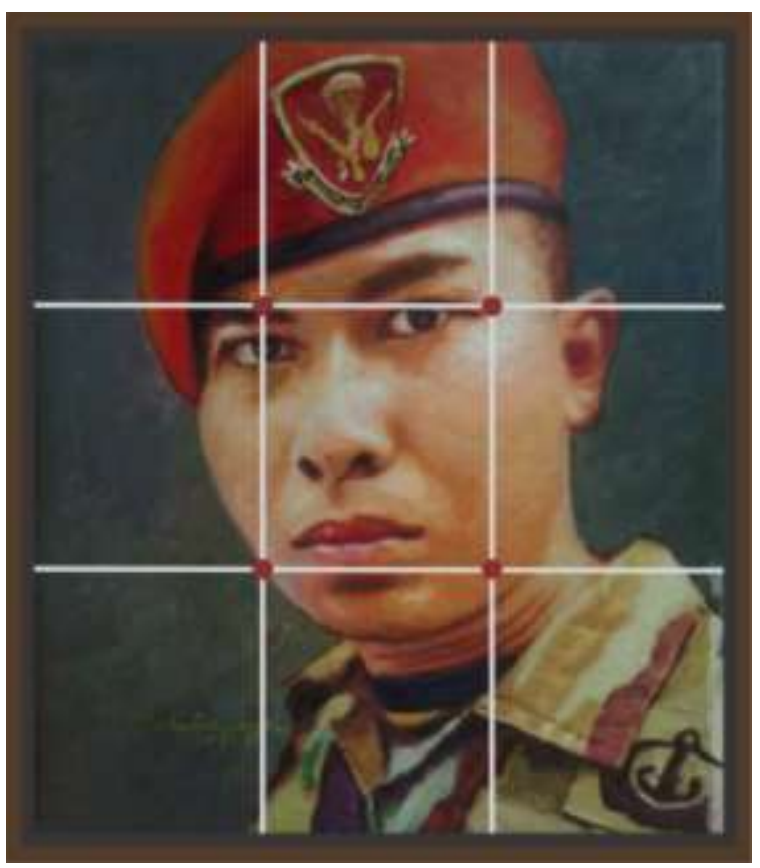

Gambar 5. Baret Merah

(Sumber: Muklisin, 2018). 


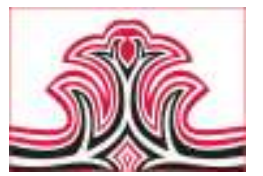

6). Karya 6

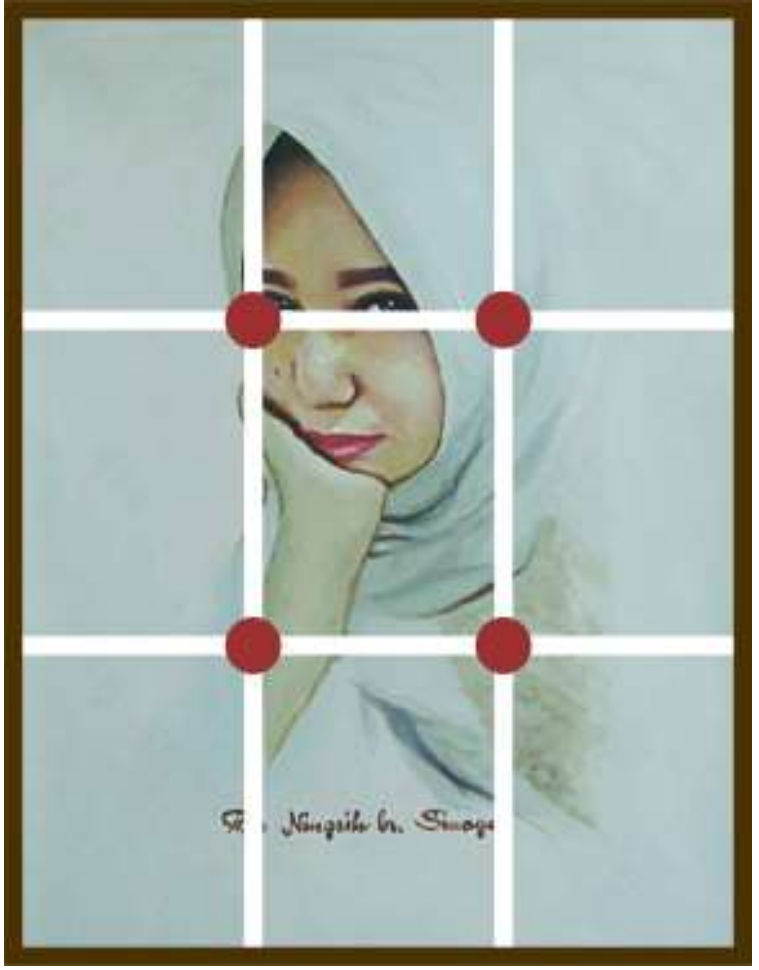

Gambar 6. Ria Ningsi

(Sumber: Andi Ian Surya, 2018).

\section{Pembahasan}

\section{1). Penari Bali}

Lukisan potret yang dikerjakan pada tahun 2013 ini merupakan karya Andi Ian Surya yang berjudul "Penari Bali" dengan bidang kanvas yang berukururan $60 \mathrm{~cm} x$ $80 \mathrm{~cm}$. Objek yang berada pada lukis an ini merupakan seorang penari pendet asal Bali, tari pendet adalah tari tradisional asal Bali.

Penggunaan warna hue pada lukis an ini dapat dilihat dari beberapa bagian seperti padabagian asesoris Andi menggunakan warna hue secara detail bagian demi bagian seperti dari warna kuning menuju ke warna merah berarti dalam hal itu huenya telah berubah berdasarkan spektrumnya kemudian dikombinasikan dengan nilai warna value untuk bagian yang terkesan terkena cahaya atau bagian terangnya dan gelabnya dengan menggunakan nilai value bekis ar 4 hingga 8 . Untuk penggunaan Warna chroma pada lukisan ini terdapat pada bagian bibir dimana warna merah primer dicampur dengan warna ungu kemerahan dan puth sehingga membentuk nilai chroma bekisar 2 hingga 14 . Goresan kuas pada lukisan ini membentuk garis lengkung dan garis lurus hal tersebut mempengani goresan yang sedikit kasar pada bagian bagian tertentu seperti pada background sisi kanan terlihat goresan
Gorga : Jurnal Seni Rupa

Volume 09 Nomor 02 Juli-Desember 2020

p-ISSN: 2301-5942 | e-ISSN: 2580-2380

yang kasar hal tersebut terjadi karena Andi ingin mempresentasi gerak dari objek yang dilukiskannya.

Lukisan ini memiliki tekstur nyata meskipun pada bagian bagian tertentu memiliki tekstur semu. Tekstur nyata sangat terlihat dan terasa pada bagian sisi kanan atas yaitu pada bagian background pada bagian bagrond lebih terlihat kasar karena pada titik itu penggoresan cat ditebalkan.

Gelap-terang yang ada pada lukisan ini terjadi dari warna, teksur dan kontras pada lukisan sehingga menimbulkan gelap terang. Komposisi dalam lukisan ini menggunakan komposisi asimetris.

\section{2). Pasar Berastagi}

Lukisan ini dibuat pada tahun 2016 menggambarkan keadaan pasar sayur tradisional yang terdapat di daerah berastagi tanah karo.Penggambaran tersebut meliputi ekspresi wajah serta aktivitas perdagang an pada sore hari. Lukisan pasar tradisional bukan pekerjaan yang mudah, berbagai eks presinya, Warna tint pada lukisan ini bany ak dijumpai yakni objek yang terkesan terkena cahaya hal tersebut terjadi karena kesan cahaya yang membuyar pada objek lukis an ini sang at tampak. Nilai Tint dari lukisan ini berkisar dari angka 7 hingga menuju angka 9. Sedangkan shade pada lukis an ini memiliki angka berkis ar angka 2 sampai 5 . Shade pada lukisan ini berfungsi sebagai warna gelap atau berfungsi sebag ai warna gelap bagian gelap pada objek yang dilukiskan.Untuk penggunaan Skema Wama chroma pada lukisan ini juga dapat kita jumpai pada bagian penutup kepala,pakaian serta buah dan objek sayur mayur yang memiliki nilai chroma bekisar 0 hingga 15.

Goresan kuas pada lukisan ini memiliki gores an kuas yang kasarnamun tetap menunjukan bentuk objek yang dilukis.Representasi dari gerak objek yang ada pada lukis an ini divisualkan ke dalam bentuk goresan yang terasa kasar dan meliuk-liuk.

Tekstur yang ada pada lukis an ini ialah tekstur nyata karena jika lukisan tersebut diraba maka akan sangat terasa kasar. Tekstur pada lukisan ini terjadi atau tercipta dari cat yang digunakan nya yang dig oreskan sedikit tebal pada bagian bagian tertentu.

Gelap terang yang ada pada lukisan ini dihasilkan dari warna, teksur dan kontras pada lukisan sehingga menimbulkan gelap terang.

komposisi yang dipakai oleh Andi dalam lukisan ini menggunakan Komposisi radial. Komposisi radial 


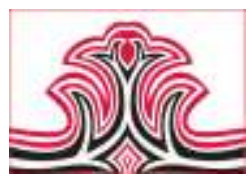

memiliki arti yang hampir sama dengan arti yang dimiliki oleh komposisi radial namun yang membedahkannya yaitu polanya tidak hanya diantara ruang sebelah kiri dan kanan saja namun juga menyediakan ruang atas dan bawah, dengan begitu komposisi juga bisa disebut dengan komposisi memancar.

\section{3). Pasar Bunga}

Lukis an pas ar bunga yang dikerjakan pada tahun 2016 ini merupakan karya Andi Ian Surya yang berjudul "Pasar Bunga" dengan bidang kanvas yang berukururan $80 \mathrm{~cm} \times 100 \mathrm{~cm}$.

Warna tint pada lukisan ini banyak dijumpai yakni objek yang terkes an terkena cahaya terutama pada objek daun daun yang memiliki warna hijau mudah, biru muda, kuning dan orange, warnaters ebut tersebut dicampur dengan skema warna putih yang memiliki nilai bekisar 6 sampai 8. Sedangkan s hade pada lukisan ini memiliki angka berkisar angka 2 sampai 5. Wama chroma pada lukisan ini juga dapat kita jumpai pada bagian baju y ang berwarna abu-abu, baju yang berwama biru dan baju yang berwarna ungu yang memiliki nilai chroma bekisar 0 hingga 17 .

Goresan kuas pada lukisan ini memiliki goresan kuas yang kasar namun tetap menunjukan bentuk objek yang dilukis.Representasi dari gerak objek yang ada pada lukisan ini divisualkan ke dalam bentuk goresan yang terasa kasar dan meliuk-liuk.

Tekstur yang ada pada lukis an ini ialah tekstur nyata karena jika lukis an tersebut diraba maka akan sangat terasa kasar. Tekstur pada lukisan ini terjadi atau tercipta dari cat yang digunakan nya yang digoreskan sedikit tebal pada bagian bagian tertentu.

Gelap terang yang ada pada lukis an ini dihasilkan dari warna, teksur dan kontras pada lukisan sehingga menimbulkan gelap terang.

komposisi yang dipakai oleh Andi dalam lukisan ini menggunakan Komposisi radial. Komposisi radial memiliki arti yang hampir sama dengan arti yang dimiliki oleh komposisi simestris namun yang membedahkannya yaitu polanya tidak hanya diantara ruang sebelah kiri dan kanan saja namun juga menyediakan ruang atas dan bawah, dengan begitu komposisi juga bisa disebut dengan komposisi memancar.
Gorga : Jurnal Seni Rupa

\section{4). Anang Sunoto}

Lukis an Andi Ian Suryayang berjudul "Anang Sunoto" menunjukan . Dengan pencahayaan dari samping figure manu sia yang terdapat pada lukisan mengand ung ritme drama kehidupan.

Warna Tint pada lukis an ini banyak dijumpai yakni objek y ang terkesan terkena cahaya seperti pada bagian baju dan wajah yang memiliki warna tint dengan nilai berkisar 6 sampai 8.Pada baju menggunakan wama dasar biru dengan percampuran skema warna puth yang memiliki nilai tint bekis ar 6 sampai 8 dan wajah memiliki warna das ar orange dengan nilai tint 6 sampai 9. Sedangkan shade pada lukis an ini y ang berada pada bagian baju memiliki nilai shade 2 sampai 5 dengan warna dasar biru.

Goresan kuas pada lukis an ini memiliki gores an kuas yang kasarnamun tetap menunjukan bentuk objek yang dilukis.Representasi dari gerak objek yang ada pada lukis an ini divisualkan ke dalam bentuk goresan yang terasa kasar dan meliuk-liuk.

Tekstur yang ada pada lukis an ini ialah tekstur nyata karena jika lukisan tersebut diraba maka akan sangat terasa kasar. Tekstur pada lukisan ini terjadi atau tercipta dari cat yang digunakan nya yang digoreskan sedikit tebal pada bagian bagian tertentu.

Gelap terang yang ada pada lukis an ini dihasilkan dan warna, teksur dan kontras pada lukisan sehingga menimbulkan gelap terang.

komposisi yang dipakai oleh Andi dalam lukisan ini menggunakan Komposisi Asimetris.

\section{5). Baret Merah}

Lukisan ini yang dikerjakan pada tahun 2017 ini merupakan karya Andi Ian Surya yang berjudul "Baret Merah" dengan bidang kanvas yang berukururan $60 \mathrm{~cm}$ x $80 \mathrm{~cm}$. Pada karya yang berjudul Baret merah benarbenar menunjukan kemampuan Andi Ian Surya dalam melukis dari segi teknik, persfektif dan pecahayaan telah mencapai keunggulan sehing gakarya ini realistis.

Wana Tint pada lukis an ini dijumpai yakniobjek y ang terkesan terkena cahaya seperti pada wajah yang memiliki warna tint dengan nilai berkisar 6 sampai 7 . Sedangkan shade pada lukis an ini yang berada pada bagian topi memiliki nilai shade 2 sampai 4 dengan warna dasar merah. Jika dipandang dari skema wama chroma maka pada lukisan ini menggunakan wama choma pada bagian loreng baju yang berwama 


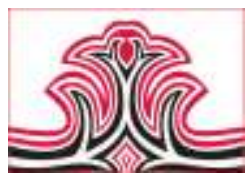

hijau,hijau tersebut memiliki nilai intensitas bekisar 7 hingga 17.

Goresan kuas pada lukisan ini memiliki goresan kuas y ang kasar namun tetap menunjukan bentuk objek yang dilukis.Representasi dari gerak objek yang ada pada lukisan ini divisualkan ke dalam bentuk goresan yang terasa kasar dan meliuk-liuk.

Tekstur yang ada pada lukis an ini ialah teks tur nyata karena jika lukisan tersebut diraba maka akan sangat terasa kasar. Tekstur pada lukisan ini terjadi atau tercipta dari cat yang digunakan nya yang digoreskan sedikit tebal pada bagian bagian tertentu.

Gelap terang yang ada pada lukis an ini dihasilkan dan warna , teksur dan kontras pada lukisan sehingga menimbulkan gelap terang. Komposisi yang dipakai oleh Andi dalam lukis an ini menggunakan Komposisi asimetris.

\section{6). Ria Ningsi}

Lukis an ini dikerjakan pada tahun 2018 ini merupakan karya Andi Ian Surya yang berjudul "Ria Ningsih" dengan bidang kanvas yang berukururan $60 \mathrm{~cm}$ x $80 \mathrm{~cm}$. Lukis an ini mengung kapkan gestur tubuh seorang gadis dalambalutan hijab bewarna putih dengan tangan yang menyanggah dagu dengan tatapan mata yang tajam.

Wana Tint pada lukis an ini dijumpai yakni objek y ang terkesan terkena cahaya seperti pada wajah yang memiliki warna tint dengan nilai berkis ar 6 s ampai 9 . Sedangkan shade pada lukisan ini yang berada pada bagian topi memiliki nilai shade 4 sampai 5 dengan warna dasar merah. Jika dipandang dari skema wama chroma maka pada lukisan ini menggunakan wama choma pada bagian loreng baju yang berwama hijau,hijau tersebut memiliki nilai intensitas bekisar 4 hingga 17.

Goresan kuas pada lukisan ini memiliki goresan kuas yang kasar namun tetap menunjukan bentuk objek yang dilukis.Representasi dari gerak objek yang ada pada lukisan ini divisualkan ke dalam bentuk goresan yang terasa kasar dan meliuk-liuk.

Tekstur yang ada pada lukis an ini ialah teks tur nyata karena jika lukis an tersebut diraba maka akan s angat terasa kasar. Tekstur pada lukisan ini terjadi atau tercipta dari cat yang digunakan nya yang digoreskan sedikit tebal pada bagian bagian tertentu.

Gelap terang yang ada pada lukis an ini dihasilkan dari warna, teksur dan kontras pada lukisan sehingga
Gorga : Jurnal Seni Rupa

Volume 09 Nomor 02 Juli-Desember 2020

p-ISSN: 2301-5942 | e-ISSN: 2580-2380

menimbulkan gelap terang. Komposisi yang dipakai oleh Andi dalam lukisan ini menggunakan Komposisi Asimetris.

\section{KESIMPULAN DAN SARAN 1.Kesimpulan}

Berdasarkan rumusan masalah, landasan teori, pembahasan dan temuan hasil penelitian, maka dapat dis impulkan sebagai berikut: 1). Warna pada lukis anlukisan Andi memiliki banyak variasi percampuran warna mulai dari hue, value, chroma, primer, sekunder, dan tersier. Kemudian Andi menggunakan teori wama komplementer, split-komplementer, triadic dan tetradic. Untuk penggunaan nilai value-tint Andi Ian Sury a s ering menggunakan warna yang bernilai 7-9 dan penggunaan value-shade Andi menggunakan nilai 2-5. Utuk nilai chroma pada lukisan Andi memiliki nilai bekis ar 7 sampai 17, 2). Gores an karya lukis karya dari Andi Ian Surya yaitu ekspresif- impresionis dengan goresan yang kasar dan tidak beraturan namun membentuk objek yang digambar, hal ini menjadi ciri khas dalam lukis an karyanya, 3). Tekstur dalam karya lukis Andi Ian Surya terdapat pada bagian tekstur nyata karena lukisan tersebut jika diraba maka akan sangat kasar permukaannya, 4). Gelap terang pada lukisan karya Andi Ian Surya dihasilkan dari percampuran warna menurut teori-teori warna warna.kemudian gelab terang pada lukisan Andi terjadi karena tekstur dan kontras pada lukisan sehingga menimbulkan gelapterang, dan Komposisi pada karya lukisan Andi Ian Surya menggunakan komposisi asimetris dan menggunakan komposisi radial.

\section{Saran}

Bagikalangan akademik dis arankan kepada mahasiswa agar menyadari dan mengenali karya-karya lukisan seniman dari daerah sendiri sebagai acuan untuk berkreasi dalam bidang berkarya lukis demi menyampaikan gagasan.Karena seni lukis selalu berkembang begitu juga dengan alat-alat yang digunakan untuk berkarya lukis.Mengenali medium berkarya lukis merupakan hal penting yang harus dipahami sebelum menciptakan sebuah karya. Konsep berkarya setiap seniman berbeda-beda, dan memilih cara nya masing-masing. Mengolah dan mengubah cara pemakaian alat-alat yang digunakan untuk menyapukan cat pada kanvas tidak semata-mata harus berdasarkan kasat mata saja, karena goresan-goresan pada setiap lukisan merupakan bagian dari konsep berkarya seorang seniman.

Dalam hal ini, penulis member sedikit saran bahwa pengenalan terhadap alat-alat yang digunakan untuk menyapukan cat pada kanvas harus dipahami, karena 
setiap alat yang digunakan sifatnya tidak serbaguna, dan tidak menutup kemungkinan sebuah alat yang lazim digunakan bis a menciptakan beragam goresangoresan yang diinginkan.

Untuk pemerintah kota Medan dan mas yarakat umum sudah seharusnya menyadari bahwa di sekitar kita tidak terlepas darikarya-karya seni, begitu ju ga deng an karya lukis. Membudayakan pengenalan terhadap karyakarya seni sejak dini akan menja diimfuls yang sangat berpengaruh pada masyarakat.

\section{DAFTAR RUJUKAN}

Bahari, Nooryan. (2014). Kritik Seni. Yogyakarta: Pustaka Pelajar.

Halawa, W. E., Triyanto, R., Budiwiwaramulja, D., \& Azis, A. C. K. (2020). Analis is Gambar Ilustrasi Hombo Batu Nias Gunungsitoli. Gorga : Jurnal Seni Rupa, 9(1), 193-203.

Kartika, S. Dharsono. (2004). Seni Rupa Modern. Bandung: Rekayasa Sains.

Kartika, S. Dharsono. (2007). Kritik Seni. Bandung: Rekayasa Sains.

Soedarso. (1990). Pengertian Seni. Yogy akarta: STSRI ASRI.

Sus anto, Mieke. (2012). Diksi Rupa. Yogyakarta: Dicti Art Lab.

Wiratno, Tri Aru (2020) Kritik Seni Rupa Berbasis Budaya Kritis. Surabaya: Scopindo Media Pustaka. 